\title{
One-Pot Stepwise Synthesis of $\gamma$-Lactams through Cycloadditions with Ketenes
}

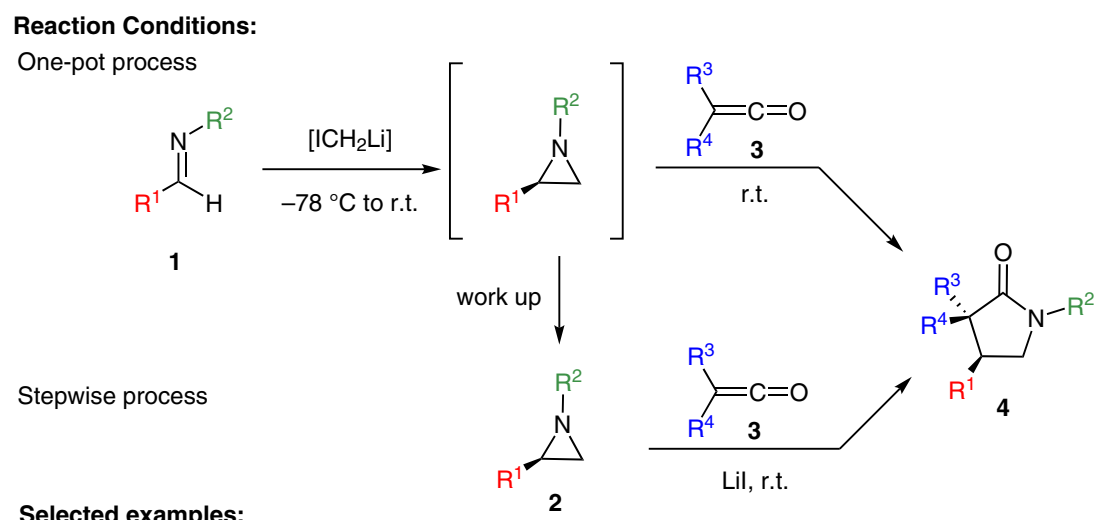

Selected examples:

2

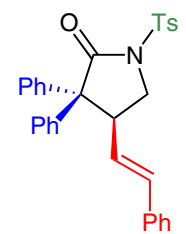

$4 a, 88 \%$ yield $^{a}$ $65 \%$ yield $^{\text {b }}$

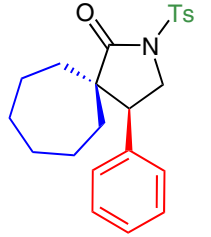

4b, $80 \%$ yield $^{\mathrm{a}}$<smiles>CCN1CC(c2ccccc2)C(c2ccccc2)C1=O</smiles>

$4 c, 60 \%$ yield $^{c}$

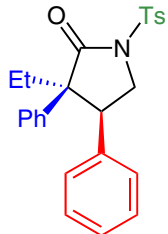

4d, $86 \%$ yield $^{\mathrm{a}}$ $\mathrm{dr}>99: 1$

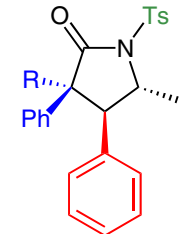

$\mathrm{R}=\mathrm{Ph}: \mathbf{4 e}, 76 \%$ yield $^{\mathrm{a}}$ dr $>99: 1$ $R=$ Et: $\mathbf{4 f}, 57 \%$ yield $^{\mathrm{a}}$ $\mathrm{dr}>99: 1$

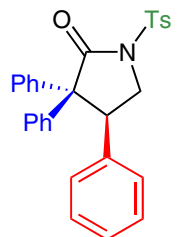

(S)-4g $84 \%$ yield $^{\mathrm{a}}, 97 \%$ ee
Key words

lactams

cycloaddition

aziridines

ketenes
Significance: Ketenes are commonly used in the synthesis of $\beta$-lactams through a [2+2] cycloaddition reaction. A subsequent ring expansion can then be triggered to give the corresponding $\gamma$-lactams. A more-direct synthetic route to these heterocycles has been developed by reacting ketenes with aziridines in a $[3+2]$ cycloaddition reaction in either a stepwise or a one-pot fashion. The latter circumvents the need for isolation of potentially unstable aziridines. A further advantage of the onepot approach is that with unsymmetrical ketenes, the reaction is highly diastereoselective. Additionally, two examples of trisubstituted $\gamma$-lactams, $4 \mathbf{e}$ and $\mathbf{4 f}$, were shown to react with high diastereoselectivity. Finally, the stereospecificity of the reaction was explored by using enantiopure aziridine (S)-2, which gave the corresponding $\gamma$-lactam with minimal erosion of enantiopurity.
Comment: The proposed reaction pathway can potentially lead to several regioisomers. The ring opening of the aziridine might occur at C2 or C3, and the addition onto the ketene might occur at either the $\mathrm{C}=\mathrm{C}$ bond or the $\mathrm{C}=\mathrm{O}$ bond. Moreover, there is the additional challenge of diastereoselectivity once the desired regioisomer is formed. Despite these challenges, the present method is broadly applicable to various ketene and aziridine substrates. This approach also demonstrates flexibility as to the choice of a one-pot or stepwise approach, the comparative yields from which highlight their complementarity. Additionally, the impressive diastereo- and enantioselectivity of the reaction showcases the growing potential of this more-convenient approach towards the synthesis of $\gamma$-lactams. 